\title{
A giant solitary vellus hair cyst on the nasal root
}

\author{
Jong Yun Choi, \\ Won Jin Cha, \\ Hyo Jeong Kwon, \\ Bommie Florence Seo, \\ Ho Kwon, \\ Sung-No Jung \\ Department of Plastic and \\ Reconstructive Surgery, College of \\ Medicine, The Catholic University of \\ Korea, Seoul, Korea
}

\begin{abstract}
Eruptive vellus hair cyst is a rare lesion of the vellus hair follicles as a result of developmental abnormality. This cyst is usually found in children, adolescents, and young adults most commonly involving the chest, upper and lower extremities, and abdomen. Herein, we introduce a 22-year-old male patient with a mass of nasal root, growing since childhood. The mass has grown over the years, causing the protruding of the nasal root contours, leading to decline in the patient's aesthetic and mental quality of life. In response, we performed complete resection of the mass, which pathologically was a vellus hair cyst. The patient is now satisfied with his appearance and there was no local recurrence during follow up.
\end{abstract}

Keywords: Cyst / Hair / Hair follicle

\section{INTRODUCTION}

Vellus hair cyst is a benign neoplasm originating in vellus hair follicles. It usually appears as a skin eruption with 1-4 mm multiple flesh-colored or yellowish papules and small nodules originating in the vellus hair follicles [1]. They comprise stratified squamous epithelium with a granular layer surrounding a cystic space filled with laminated keratin and a variable number of vellus hair shafts, pathologically speaking [2]. In addition to the typical form, solitary-specific tumors have been introduced several times. We report the rare case of vellus hair cyst that showed unique morphological features as a large solitary mass on the nasal root.

\section{CASE REPORT}

A 22-old-year male patient visited for evaluation of a painless bulging mass on the nasal root (Fig. 1). The mass has been gradually increasing in size in the past 10 years. He had no oth-

\section{Correspondence: Sung-No Jung}

Department of Plastic and Reconstructive Surgery, Uijeongbu St. Mary's Hospital, College of Medicine, The Catholic University of Korea, 271 Cheonbo-ro, Uijeongbu 11765 , Korea

E-mail: jsn7190@catholic.ac.kr

Received July 20, 2020 / Revised September 9, 2020 / Accepted October 5, 2020 er medical history or inheritance of milia or skin lesion.

We performed magnetic resonance imaging which revealed an approximately $1.3 \times 2.2 \times 2.2 \mathrm{~cm}$ T1 high signal intensity mass in the nasal root, low signal intensity in contrast enhanced fat-saturation T1 weight image, suggesting a fat component (Fig. 2). The mass has grown over the years, causing protrusion of the nasal root contours, leading to a decline in the patient's aesthetic and mental quality of life.
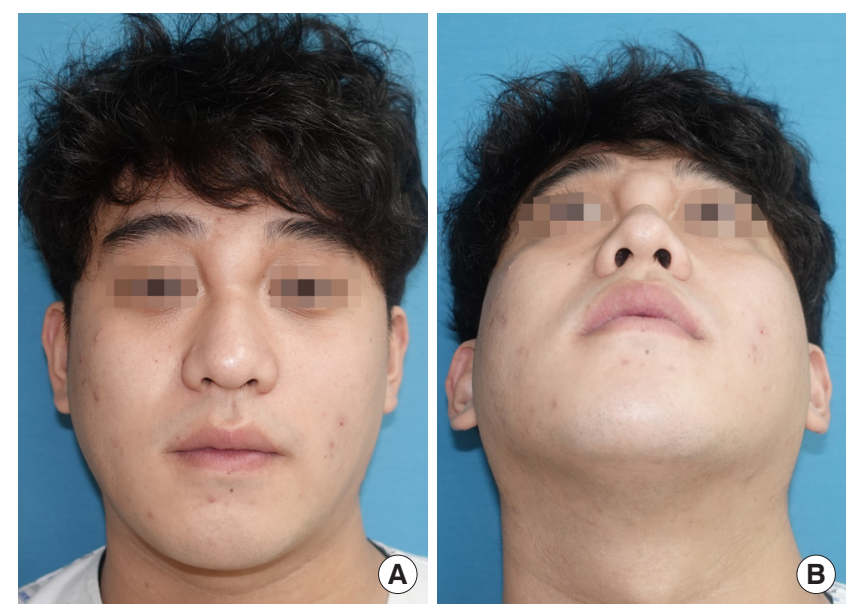

Fig. 1. Photographs showed an approximately $2 \mathrm{~cm}$ round, bulging mass on the patient's nasal root. (A) Anterior-posterior view. (B) Worm's eye view. 

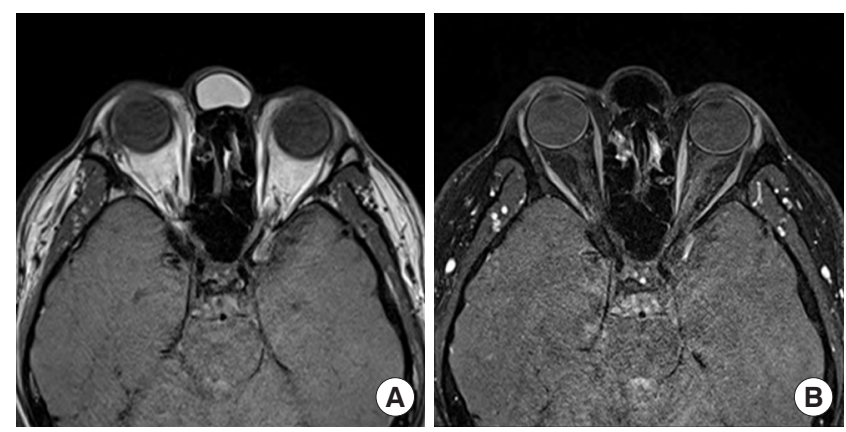

Fig. 2. Magnetic resonance imaging showed an approximately $1.3 \times 2.2 \times 2.2 \mathrm{~cm}$ T1 high signal intensity mass in the nasal root and low signal intensity in contrast enhanced fat-saturation $\mathrm{T} 1$ weight image. (A) T1 axial view and (B) contrast enhanced fat-saturation T1 axial view.
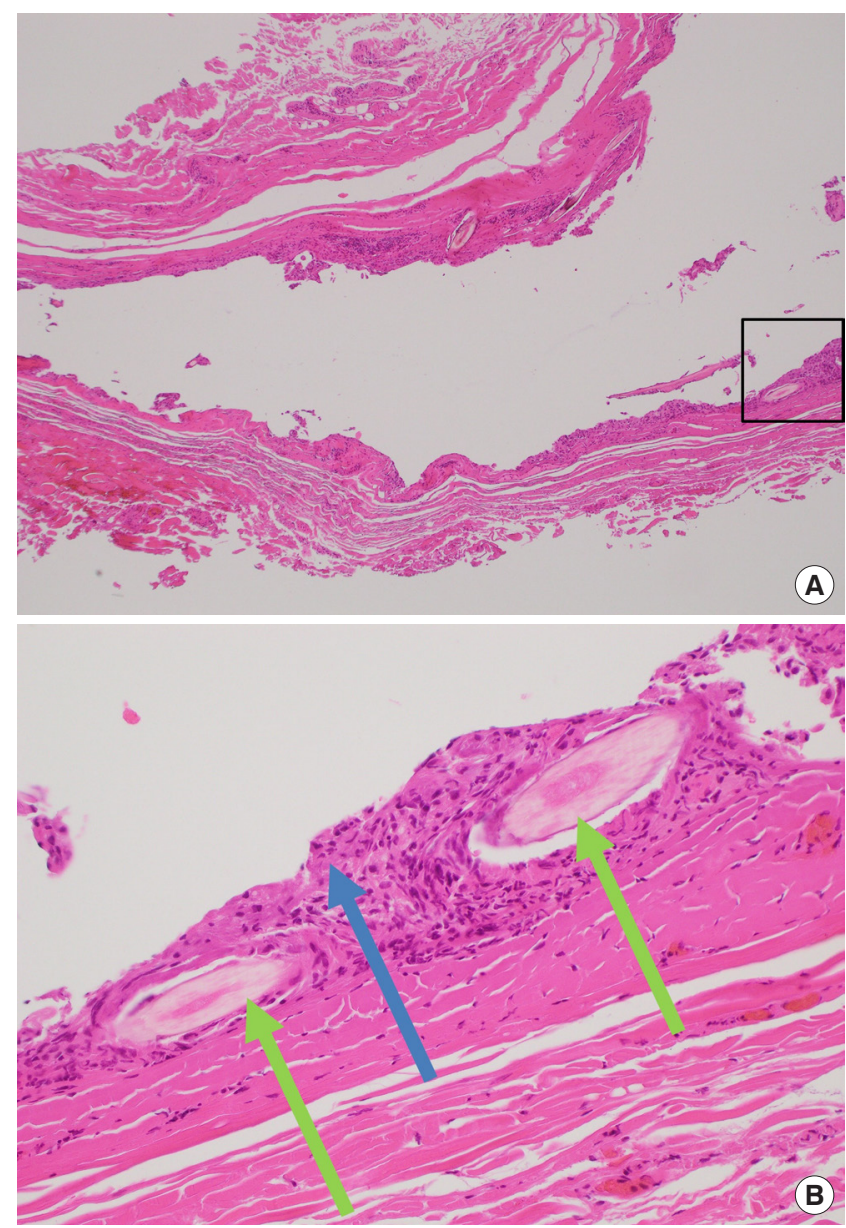

Fig. 3. Histopathological features of the excised tumor. (A) A cyst lined by stratified squamous epithelium $(\mathrm{H} \& \mathrm{E}, \times 40)$. (B) Magnified view of the area within the rectangle in (A). A cyst lined by stratified squamous epithelium comprises laminated keratin (blue arrow) and a variable number of vellus hair shafts (light green arrows) (H\&E, $\times 200)$.

We performed complete resection of this mass under general anesthesia. The main cyst was totally excised with the draining

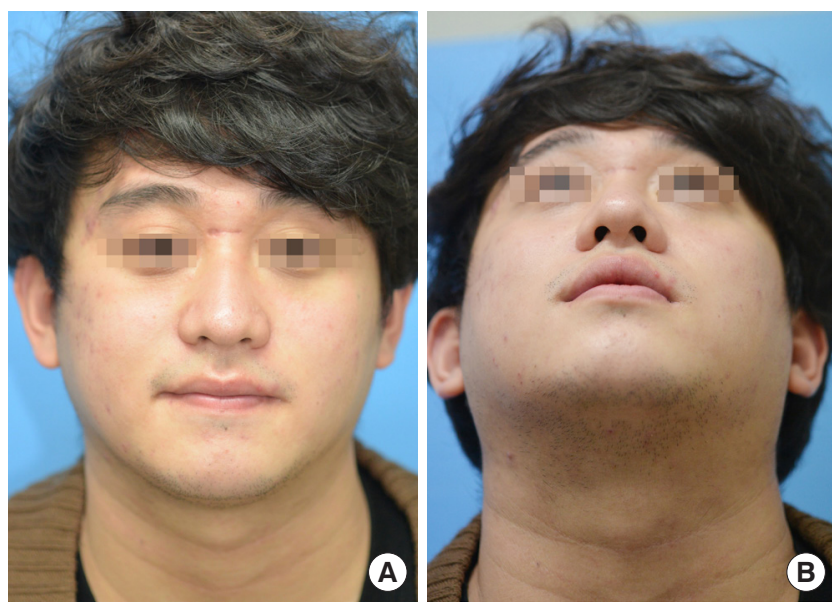

Fig. 4. Photographs 6 months after surgery. (A) Anterior-posterior view. (B) Worm's eye view.

of yellowish thick fluid. The tumor was an irregular tan-gray cystic mass fragment with $2.3 \times 1.0 \times 0.5 \mathrm{~cm}$. And histopathological examination showed 5 to 7 layered stratified squamous epithelium comprising laminated keratin material and several vellus hair shafts, consistent with a vellus hair cyst (Fig. 3).

Six months after the operation, the bulging feature was resolved and there was no local recurrence during the postoperative follow-up and no additional complications (Fig. 4).

\section{DISCUSSION}

Vellus hair cyst was first described as an eruptive type lesion in 1977 by Esterly et al [3]. Demographically, eruptive vellus hair cyst presents clinically in a rather monomorphous fashion, round, dome-shaped, skin-colored, asymptomatic, soft-tender papules with a smooth surface and grouped or disseminated in a symmetric pattern [2].

It inherits as an autosomal dominant trait and sporadic cases usually appear at age $4-18$ broadly. In recent studies, some cases have been reported several times as solitary vellus hair cyst [46]. And similar to this case, the giant solitary vellus cyst on the lower abdomen was reported in 2013 in Korea [7].

Vellus hair cyst is likely to arise in many hair follicles as this case occurs on the medial side of the eyelids with abundant follicles. But it can occur in any part of the body. An eruptive vellus hair cyst involving ocular adnexa was reported in 2017 [8].

Also, vellus hair cyst has been reported in several cases as being associated with multiple tumors rather than as single pathologic finding. For example, Kiene et al. [9] reported a hybrid cyst showing overlapping histologic features of vellus hair cysts and steatocystoma multiplex, and suggested that they are variants of one entity. Because of this characteristic, it is difficult for 
vellus hair cyst to be defined as just one entity and thus, needs differential diagnosis from other tumors histologically [10-12].

First, steatocystoma's histologic findings are the sebaceous gland connecting to the cyst lining but the pillar structures and hair contents are not observed. It can differ from the vellus hair cyst [9]. Second, epidermal inclusion cyst is easy to distinguish from vellus hair cyst because no hair fragments are observed [13]. The difference from the pigmented follicular cyst is the pigmentation of the hair shaft. Last, dermoid cyst has lining lacking a granular layer and is lined by stratified squamous epithelium with associated hair follicles and sebaceous glands. Hair shafts are often found within the cyst. However, they are easily differentiated by the presence of multiple adnexal structures within the cysts' wall [14]. About $25 \%$ of eruptive vellus hair cysts resolve spontaneously, may be through transepidermal elimination. But if solitary giant cyst such as case is present in an area where cosmetic problems may occur, an excisional biopsy is required [15].

\section{NOTES}

\section{Conflict of interest}

No potential conflict of interest relevant to this article was reported.

\section{Ethical approval}

The study was approved by the Institutional Review Board of the Catholic University of Korea Uijeongbu St. Mary’s Hospital (IRB No. UC20ZASA0064) and performed in accordance with the principles of the Declaration of Helsinki. Written informed consent was obtained.

\section{Patient consent}

The patient provided written informed consent for the publication and the use of his images.

\section{ORCID}

$\begin{array}{ll}\text { Jong Yun Choi } & \text { https://orcid.org/0000-0002-1164-4499 } \\ \text { Won Jin Cha } & \text { https://orcid.org/0000-0003-0761-4251 } \\ \text { Hyo Jeong Kwon } & \text { https://orcid.org/0000-0002-5778-5692 } \\ \text { Bommie Florence Seo } & \text { https://orcid.org/0000-0002-6907-5962 } \\ \text { Ho Kwon } & \text { https://orcid.org/0000-0001-7471-0804 } \\ \text { Sung-No Jung } & \text { https://orcid.org/0000-0002-0419-4717 }\end{array}$

\section{REFERENCES}

1. Bovenmyer DA. Eruptive vellus hair cysts. Arch Dermatol 1979;115:338-9.

2. Torchia D, Vega J, Schachner LA. Eruptive vellus hair cysts: a systematic review. Am J Clin Dermatol 2012;13:19-28.

3. Esterly NB, Fretzin DF, Pinkus H. Eruptive vellus hair cysts. Arch Dermatol 1977;113:500-3.

4. Kim SY, Yun SJ, Lee JB, Kim SJ, Lee SC, Won YH. Vellus hair cysts developing on the labium major. Korean J Dermatol 2014;52:912-3.

5. Kim YJ, Lee KH, Kim JW, Koh BK. A case of solitary vellus hair cyst on the forehead. Korean J Dermatol 2004;42:347-9.

6. Lee JH, Bae MY, Lee BH, Jung MK. A large, persistent, solitary vellus hair cyst in the postauricular area. Ear Nose Throat J 2009;88:E15-7.

7. Woo YR, Lee HK, Lee JS, Koo DW, Jung KE. A giant solitary vellus hair cyst on the lower abdomen. Eur J Dermatol 2013;23: 534-5.

8. Choi R, MacLean KD, Davidson HC, Patel BCK. Vellus hair cyst of the orbit. Ophthalmic Plast Reconstr Surg 2017;33(3S Suppl 1):S89-S91.

9. Kiene P, Hauschild A, Christophers E. Eruptive vellus hair cysts and steatocystoma multiplex. Variants of one entity? Br J Dermatol 1996;134:365-7.

10. Law AM, Rutland BM, Horenstein MG. Pathologic quiz case: an 84-year-old woman with a skin cyst containing ZiehlNeelsen-positive structures. Basal cell carcinoma associated with a vellus hair cyst. Arch Pathol Lab Med 2005;129:e75-6.

11. Lee KH, Cho YK, Han YW, Jeon YJ, Kahng J, Park CJ. A case of melanocytic nevus combined with a vellus hair cyst. Korean J Dermatol 2005;43:1410-2.

12. Tsuruta D, Nakagawa K, Taniguchi S, Kobayashi H, Hamada T, Ishii M. Combined cutaneous hamartoma encompassing benign melanocytic naevus, vellus hair cyst and epidermoid cyst. Clin Exp Dermatol 2000;25:38-40.

13. McGavran MH, Binnington B. Keratinous cysts of the skin. Identification and differentiation of pilar cysts from epidermal cysts. Arch Dermatol 1966;94:499-508.

14. Lee S, Kim JG. Eruptive vellus hair cyst: clinical and histologic findings. Arch Dermatol 1979;115:744-6.

15. Sharma S, Gupta A, Jaiprakash P. Solitary eruptive vellus hair cyst in an adult-an unusual presentation: case report with a brief review of literature. Int J Health Sci Res 2015;5:733-6. 